\title{
A new eye gel containing sodium hyaluronate and xanthan gum for the management of post-traumatic corneal abrasions
}

This article was published in the following Dove Press journal:

Clinical Ophthalmology

8 May 2012

Number of times this article has been viewed

Francesco Faraldi'

Vincenzo Papa ${ }^{2}$

Debora Santoro ${ }^{2}$

Daria Rasà ${ }^{2}$

Annamaria L Mazza ${ }^{2}$

Maria M Rabbione'

Simona Russo²

'Department of Ophthalmology III, Presidio Ospedaliero Oftalmico, Torino, Italy; ${ }^{2}$ SIFI SpA, Catania, Italy
Correspondence: Vincenzo Papa Via Ercole Patti 36, I-95020 Aci San Antonio (CT), Italy

Tel +39095 792 2III

$\mathrm{Fax}+39095789345$ I

Email vincenzo.papa@sifigroup.com
Purpose: The aim of this study was to investigate the effects of an ophthalmic gel containing sodium hyaluronate and xanthan gum in addition to the antibiotic netilmicin in the management of traumatic corneal abrasions.

Patients and methods: Patients with traumatic corneal abrasions were randomly treated as follows: Group A ( $\mathrm{n}=20)$ with an occlusive patching for 12 hours plus one drop of an eye gel containing $0.15 \%$ sodium hyaluronate, $1 \%$ xanthan gum and $0.3 \%$ netilmicin qid for 5 days; and Group B $(\mathrm{n}=20)$ with an occlusive patching for $2-3$ days plus one application of $0.3 \%$ netilmicin ophthalmic ointment qid for 5 days. All patients were evaluated after the third and seventh day by slit-lamp examination, fluorescein staining, and corneal defect photograph in order to assess corneal re-epithelialization. Conjunctival hyperaemia, lid oedema, subjective symptoms of discomfort, and conjunctival swabs were also evaluated.

Results: No statistically significant difference was observed between the groups in terms of the extent of corneal healing after 3 days of treatment. Both treatments were also highly effective in decreasing the erosion score and the conjunctival hyperemia $(P<0.0001, P<0.005$, respectively) without any significant difference between the two types of treatment. Subjective symptoms of discomfort and conjunctival swabs were also evaluated.

Conclusion: In the management of traumatic corneal abrasions, the administration of an eye gel containing sodium hyaluronate and xanthan gum is able to reduce the length of occlusive patching. In addition, the presence of netilmicin guarantees good antibiotic prophylaxis during the wound repair process.

Keywords: netilmicin, xanthan gum, wound healing, patching, corneal abrasion

Corneal abrasion is a defect of the corneal epithelial surface, accounting for approximately $10 \%$ of the visits to eye emergency units. It is characterized by acute ocular pain and other symptoms of discomfort affecting the quality of life of patients. ${ }^{1}$ Simple corneal abrasions rarely become complicated, and in most cases a complete recovery occurs in few days.

An abundance of literature suggests different regimens of corneal abrasion treatment. $^{2-8}$ Thus, treatment is mostly by individual choice. Eye patching is perhaps the most controversial issue in the treatment of corneal abrasions. ${ }^{4-8}$ However, a recent survey indicated that, even in absence of reproducible scientific evidence, this procedure remains the mainstay of corneal abrasion management in combination with topical antibiotic, cycloplegic, and oral analgesics. ${ }^{2}$

The aim of our study was to investigate the possibility of reducing the length of patching by using an eye gel that is able to both promote wound healing and prevent 
ocular infections. This gel has no preservative and contains two natural biopolymers (xanthan gum and sodium hyaluronate) in addition to netilmicin. Hyaluronate is well known for promoting physiological wound healing by stimulating corneal epithelial cell migration and proliferation, ${ }^{9-11}$ whereas netilmicin is an effective, safe, and noncytotoxic antibiotic that is able to provide good protection against bacterial infections during the process of wound repair. ${ }^{12-15}$

\section{Material and methods \\ Patients}

Our study enrolled 40 consecutive patients with a traumatic or foreign body removal-related corneal abrasion (occurring within 24 hours of the beginning of the study and not caused by thermal, radiant, or caustic agents) that spared the Bowman membrane and the limbus, and involved $<50 \%$ of the cornea and with corneal fluorescein uptake. The patients were of either sex and aged between 18 and 55 years. Patients were randomly assigned to two treatment groups with different lengths of time of patching. The first group $(n=20)$ dressed an occlusive patch $\left(\right.$ Eycopad $^{\circledR}$; Hartmann AG, Heidenheim, Germany) for only 12 hours and received one application of an eye gel containing $0.15 \%$ sodium hyaluronate, $1 \%$ xanthan gum, and $0.3 \%$ netilmicin (Xanternet; SIFI SpA, Catania, Italy) qid for 5 days. The second group $(n=20)$ dressed the same occlusive patch for 3 days. In this group, the antibiotic prophylaxis was ensured by the use of $0.3 \%$ netilmicin ophthalmic ointment (Nettavisc; Eyelab SrL, Milan, Italy) qid for 5 days. The protocol was approved by the local ethics committee, and all patients gave written informed consent according to the Declaration of Helsinki.

\section{Evaluation}

All patients were evaluated three times in a period of 7 days (Day 1, Day 3, and Day 7). During the enrolment visit (Day 1), patients were subjected to a slit lamp (SL990 digital, CSO Srl, Florence, Italy) examination of both eyes. A slit-lamp examination was also performed on the fellow (non-injured) eye to ensure the absence of corneal dystrophies or other corneal pathology. In case of eligibility, patients started the assigned treatment. Before starting treatment, corneal defects were stained with fluorescein and photographed by a digital camera connected to the slit lamp microscope (CSO Srl, Firenze, Italy). The total surface area of the epithelial defect $\left(\mathrm{mm}^{2}\right)$ was measured (Figure 1) using Epsilon Lyrae software (Version 1.0, CSO Srl, Florence, Italy). The extent of punctate erosions was evaluated according to the National Eye Institute/Industry Workshop system. ${ }^{16}$ A standardized grading system $(0=$ none,

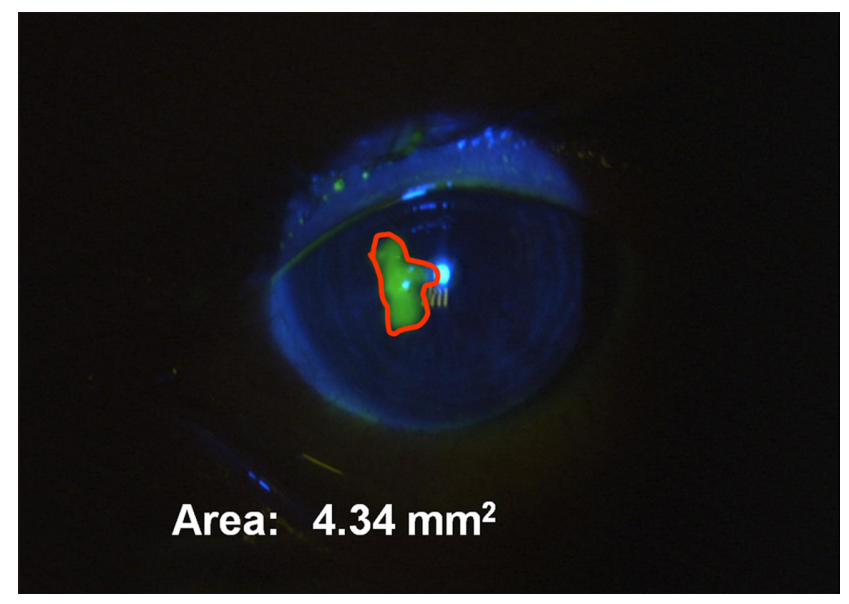

Figure I Measurement of epithelial defect.

Notes: Epithelial defects were stained with fluorescein (green) and photographed by a digital camera connected to the slit lamp microscope. The surface area of the defect (red area) was measured $\left(\mathrm{mm}^{2}\right)$ by using Epsilon Lyrae software (Version I.0, CSO Srl, Florence, Italy).

$1=$ trace, $2=$ mild, $3=$ moderate, $4=$ severe) was used for each of the five areas of the cornea and a summary score was then calculated. At Day $3 \pm 1$ and Day $7 \pm 1$, slit lamp examination, corneal fluorescein staining, and photograph were repeated. A unique independent operator was involved in the evaluation of corneal re-epithelialization in a blind manner. At all visits, the degree of conjunctival hyperaemia and lid edema were evaluated by using a categorical grading scale $(0=$ none, 1 = mild, $2=$ moderate, $3=$ severe). Subjective symptoms of ocular discomfort (pain, foreign body sensation, tearing, and photophobia) were also evaluated by a visual analogue rating scale (VARS). Conjunctival swabs (BD CultureSwab ${ }^{\text {TM; }}$; Becton Dickinson and Company, Sparks, MD, USA) were also performed at Day 1 and Day $7 \pm 1$ to rule out bacterial ocular infections.

\section{Statistics}

Statistical analysis was performed by a qualified statistician (DS) using the SAS software (version 9.1, SAS Institute Inc, Cary, NC). All statistical tests were two-sided, with a 5\% significance level and were regarded as descriptive only, according to the exploratory nature of the study. The primary clinical parameter considered in the study was the extent of corneal reepithelialization at Day $3 \pm 1$. The total surface area of the epithelial defect was measured $\left(\mathrm{mm}^{2}\right)$ and compared within and between each treatment group, by a Wilcoxon test for paired or independent observations, respectively. The extent of corneal punctate erosions (erosion score), the degree of conjunctival hyperemia, lid edema, and the evaluation of subjective symptoms of ocular discomfort were also evaluated by a Wilcoxon signed rank, 
considering assessments at Day 1 as baseline evaluation. The percentage of patients with ocular infections was compared between the 2 groups using Fisher's exact test. The primary population for analyzing the performance included subjects who were visited and received treatments for $3 \pm 1$ days (full analysis data set). Safety analysis was done on all patients who received at least one dose of the treatment.

\section{Results}

The demographic characteristics of all randomized patients are displayed in Table 1; no significant differences were observed between the 2 treatment groups. Four patients (two in each group) did not complete the study because of lack of follow up, and therefore the efficacy analysis was performed on 36 patients.

The area of the lesion (Figure 2) at the beginning of the study was $2.56 \pm 2.80 \mathrm{~mm}^{2}$ in the group treated with the eye gel and $1.75 \pm 2.06 \mathrm{~mm}^{2}$ in the control group (full analysis data set). After 3 days, both treatments were highly effective in decreasing the total surface area of the epithelial defect $\left(0.07 \pm 0.27\right.$ versus $0.04 \pm 0.07 \mathrm{~mm}^{2}$, respectively: $P<0.0001$, Wilcoxon signed rank test), whereas no statistically significant differences were observed between the two treatment groups $(P=0.367)$.

With regard to the corneal reepithelialization, both treatments were highly effective in decreasing the erosion score and the conjunctival hyperemia $(P<0.0001$ and $P<0.005$, respectively: Wilcoxon signed rank test; Table 2$)$. No differences were observed between the 2 treatment groups $(P=0.752$ and $P=0.888$ for erosion score and conjunctival hyperemia, respectively).

Finally, all symptoms of ocular discomfort (pain, foreign body sensation, tearing, and photophobia) decreased to the

Table I Demographics (all randomized patients)

\begin{tabular}{llll}
\hline & $\begin{array}{l}\text { Short patching } \\
\text { plus eye gel }\end{array}$ & $\begin{array}{l}\text { Regular } \\
\text { patching }\end{array}$ & Total \\
\hline $\begin{array}{l}\text { Number of patients } \\
\text { Gender (number,\%) }\end{array}$ & 20 & 20 & 40 \\
$\quad$ Male & $17(85 \%)$ & $19(95 \%)$ & $36(90 \%)$ \\
$\quad$ Female & $3(15 \%)$ & $1(5 \%)$ & $4(10 \%)$ \\
Age (years) & & & \\
$\quad$ Mean & 38 & 37 & 37 \\
SD & 7.60 & 9.68 & 8.59 \\
Range & $22-54$ & $23-55$ & $22-55$ \\
Area of the epithelial defect (mm²) & & \\
$\quad$ Mean & 2.55 & 1.73 & 2.14 \\
SD & 2.65 & 1.95 & 2.34 \\
Range & $0.38-9.67$ & $0.34-7.98$ & $0.34-9.67$ \\
\hline
\end{tabular}

Abbreviation: SD, standard deviation.

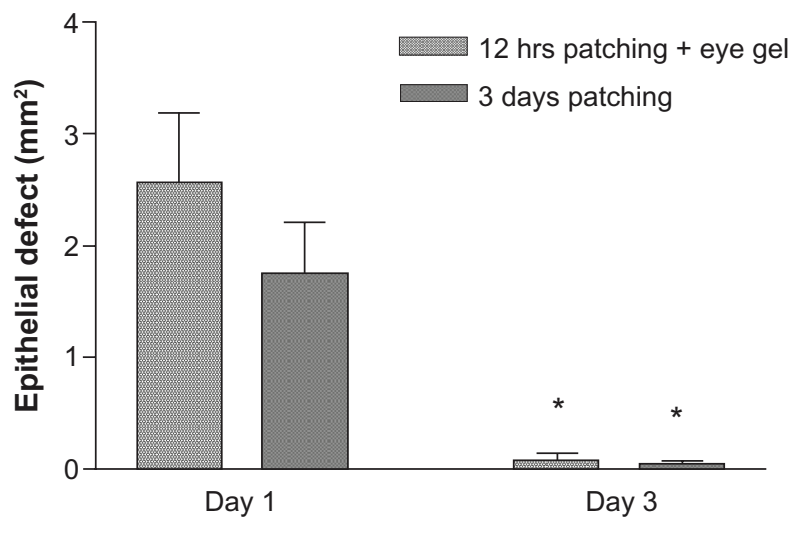

Figure 2 Effect on corneal reepithelialisation.

Notes: Corneal defect was stained with fluorescein and photographed before starting treatment (day I) and after 3 days. The total surface area of the epithelial defect $\left(\mathrm{mm}^{2}\right)$ was measured by using Epsilon Lyrae software (Version 1.0, CSO Srl, Florence, Italy). Data (full analysis data set) are expressed as mean $\pm S D$. $* P<0.000$ I, Wilcoxon signed rank test (within groups).

Abbreviation: SD, standard deviation.

same extent in a clinically significant way within each group with no differences between the patched and the nonpatched group (data not shown).

Ocular infections were detected in only 2 patients $(6 \%)$, and in both cases, the isolated bacteria were fully eradicated at the follow-up visit.

No patient experienced adverse events during the study.

\section{Discussion}

Minor trauma to the ocular surface can cause corneal abrasion. This is a commonly presented eye complaint characterized by pain, foreign body sensation, photophobia, and transient decrease in visual acuity. Classically, the standard of care for treatment of corneal abrasion has been the use of a pressure eye patch with topical antibiotic and mydriatics for 24-48 hours. ${ }^{4,8}$ These procedures remain largely prescribed although there is no strong evidence for their use., ${ }^{4,17-19}$ The indication for eye patch use is particularly controversial because it reduces corneal oxygenation and increases corneal temperature, which result in a higher chance of infection. ${ }^{2,3,6}$ In addition, the loss of binocular vision can cause a reduction in visual field and depth perception. Accordingly, recent Cochrane database systematic reviews on patching for corneal abrasion concluded that patching is not recommended for lesions smaller than $10 \mathrm{~mm}^{2} .{ }^{5}$ Other means of managing corneal abrasion have also been proposed, such as soft bandage contact lenses, which have been demonstrated to be better than patching in reducing ocular pain and promoting wound healing in large surface areas $(>4 \mathrm{~mm})$. However, there were concerns over their infection rates, costs, and need for follow up. ${ }^{20}$ 
Table 2 Effect on conjunctival hyperemia and erosion score

\begin{tabular}{|c|c|c|c|c|c|c|}
\hline & \multicolumn{3}{|c|}{ Short patching plus eye gel } & \multicolumn{3}{|c|}{ Regular patching } \\
\hline & \multicolumn{2}{|c|}{ Median (Mean \pm SD) } & \multirow[t]{2}{*}{$P$ value } & \multicolumn{2}{|c|}{ Median (Mean \pm SD) } & \multirow[t]{2}{*}{$P$ value } \\
\hline & Day I & Day 3 & & Day I & Day 3 & \\
\hline Conjunctival hyperemia & $\mathrm{I}(0.67 \pm 0.69)$ & $0(0.06 \pm 0.24)$ & $<0.005$ & $\mathrm{I}(0.72 \pm 0.57)$ & $0(0.17 \pm 0.38)$ & $<0.005$ \\
\hline Erosion score & $2(2.33 \pm 0.59)$ & $I(0.1 I \pm 0.32)$ & $<0.0001$ & $2.5(2.39 \pm 0.70)$ & $0(0.22 \pm 0.43)$ & $<0.000$ I \\
\hline
\end{tabular}

Notes: Conjunctival hyperemia was evaluated by a categorical grading scale $(0=$ none, $\mathrm{I}=$ mild, $2=$ moderate, $3=$ severe). Erosion score was calculated by adding the individual scores for punctate erosions obtained in five corneal areas as described in the Materials and Methods section. A within treatment comparison was performed using the Wilcoxon signed test.

Abbreviation: SD, standard deviation.

Collagen shields have also proven to be more comfortable than patching, but they are not used in clinical practice. ${ }^{21}$ Nevertheless, the most recently published survey on corneal abrasion management conducted in an accident and emergency department in the UK has confirmed that eye patching is still widely used in clinical practice. ${ }^{2}$

During the wound repair process, the use of a lubricant is always advisable because hydration and lubrication smooth out irregularities in the corneal epithelium, thus protecting the ocular surface from damage due to friction and desiccation. For this reason, we evaluated the effect of a lubricant eye gel in patients with corneal abrasion sparing the Bowman membrane and involving less than $50 \%$ of the cornea. This gel is available in some EU countries (Xanternet) in preservativefree unidoses containing two natural biopolymers, sodium hyaluronate and xanthan gum, in addition to aminoglycoside netilmicin. Sodium hyaluronate and xanthan gum are high molecular weight polysaccharides with water binding and mucoadhesivity properties, providing effective hydration and protection of the cornea. ${ }^{22-26}$ In addition, sodium hyaluronate is well known to promote wound healing by stimulating corneal epithelial cell migration and proliferation. ${ }^{9-11}$ Netilmicin is a broad spectrum, third generation aminoglycoside with excellent in vitro activity against the most common bacterial ocular pathogens, including Pseudomonas spp. $\cdot^{14,27-29}$ Netilmicin is noncytotoxic and does not interfere with physiological healing, and is therefore able to provide good protection against bacterial infections during the wound repair process. ${ }^{12,13,15}$

\section{Conclusion}

In the present study, we compared "routine" patching (48 to 72 hours) with short patching (12 hours), followed by a treatment with the eye gel in patients with simple corneal erosion. Corneal defects were photographed, stained with fluorescein, and measured at each control visit, allowing an objective evaluation of the wound healing. Other parameters, such as the extent of punctate erosions, conjunctival, hyperemia, lid edema, pain, and other subjective symptoms of ocular discomfort, were also evaluated throughout the study. After 3 days, the residual corneal defect and all other parameters were not statistically different.

The major limitation of the study is the trial design; the two groups of patients were not fully comparable because of the different uses of the patching regime. In addition, an evaluation of wound healing earlier than 3 days was missed. Nevertheless, our data suggest that although a reduction of the duration of patching followed by the topical administration of Xanternet eye gel does not affect the healing of the corneal defect, it does improve patient compliance. Additional clinical data with more patients comparing a group treated with the eye gel with a nonpatched group are required to recommend the eye gel as unique tool in the management of traumatic corneal abrasions.

\section{Acknowledgments}

We thank Dr Eileen Colazzo for her writing assistance.

\section{Disclosure}

Vincenzo Papa, Daria Rasà, Debora Santoro, Annamaria L Mazza, and Simona Russo are or were employees of SIFI SpA.

\section{References}

1. Chiapella AP, Rosenthal AR. One year in an eye casualty clinic. $\mathrm{Br} J$ Ophthalmol. 1985;69:865-870.

2. Thyagarajan SK, Sharma V, Austin S, et al. An audit of corneal abrasion management following the introduction of local guidelines in an accident and emergency department. Emerg Med J. 2006;23:526-529.

3. Calder L, Balasubramanian S, Stiell I. Lack of consensus on corneal abrasion management: results of a national survey. CJEM. 2004;6(6): 402-407.

4. Wilson SA, Last A. Management of corneal abrasions. Am Fam Physician. 2004;70:123-128.

5. Turner A, Rabiu M. Patching for corneal abrasion. Cochrane Database Syst Rev. 2006;19(2):CD004764.

6. Flynn CA, D'Amico F, Smith G. Should we patch corneal abrasions: a meta-analysis. J Fam Pract. 1998;47(4):264-270.

7. Soli C, Herbert ME. Myth: corneal abrasions require routine patching. West J Med. 2001;174(3):207.

8. Fraser S. Corneal abrasion. Clin Ophthalmol. 2010;4:387-390.

9. Nishida T, Nakamura M, Mishima $H$, et al. Hyaluronan stimulates corneal epithelial migration. Exp Eye Res. 1991;53(6):753-758. 
10. Camillieri G, Bucolo C, Rossi S, et al. Hyaluronan-induced stimulation of corneal wound healing is a pure pharmacological effect. $J$ Ocul Pharmacol Ther. 2004;20(6):548-553.

11. Stiebel-Kalish H, Gaton DD, Weinberger D, et al. A comparison of the effect of hyaluronic acid versus gentamicin on corneal epithelial healing. Eye. 1998;12(Pt 5):829-833.

12. Leonardi A, Papa V, Fregona I, et al. In vitro effects of fluoroquinolone and aminoglycoside antibiotics on human keratocytes. Cornea. 2006; 25(1):85-90.

13. Scuderi AC, Paladino GM, Marino C, et al. In vitro toxicity of netilmicin and ofloxacin on corneal epithelial cells. Cornea. 2003;22(5): 468-472.

14. Papa V, Aragona P, Scuderi AC, et al. Treatment of acute bacterial conjunctivitis with topical netilmicin. Cornea. 2002;21(1):43-47.

15. Papa V, Leonardi A, Getuli C, Pacelli V, Russo P, Milazzo G. Effect of ofloxacin and netilmicin on human corneal and conjunctival cells in vitro. J Ocul Pharmacol Ther. 2003;19(6):535-545.

16. Lemp MA. Report of the National Eye Institute/Industry Workshop on clinical trials in dry eye. CLAO J. 1995;21(4):221-232.

17. Kruger RA, Higgins J, Rashford S, Fitzgerald B, Land R. Emergency eye injuries. Aust Fam Physician. 1990;19(6):934-938.

18. King JWR, Brison RJ. Do topical antibiotics help corneal epithelial trauma? Can Fam Physician. 1993;39:2349-2352.

19. Carley F, Carley S. Towards evidence based emergency medicine: best BETs from the Manchester Royal Infirmary. Mydriatics in corneal abrasion. Emerg Med J. 2001;18(4):273.

20. Acheson JF, Joseph J, Spalton DJ. Use of soft contact lenses in an eye casualty department for the primary treatment of traumatic corneal abrasions. Br J Ophthalmol. 1987;71(4):285-289.
21. Wedge CI, Rootman DS. Collagen shields: efficacy, safety and comfort in the treatment of human traumatic corneal abrasion and effect on vision in healthy eyes. Can J Ophthalmol. 1992;27(6):295-298.

22. Guillaumie F, Furrer P, Felt-Baeyens O, et al. Comparative studies of various hyaluronic acids produced by microbial fermentation for potential topical ophthalmic applications. J Biomed Mater Res. 2010;92(4): 1421-1430.

23. Nakamura M, Hikida M, Nakano T, Ito S, Hamano T, Kinoshita S. Characterization of water retentive properties of hyaluronan. Cornea. 1993;12(5):433-436.

24. Goa KL, Benfield P. Hyaluronic acid. A review of its pharmacology and use as a surgical aid in ophthalmology, and its therapeutic potential in joint disease and wound healing. Drugs. 1994;47(3):536-566.

25. Saettone MF, Monti D, Torracca MT, Chetoni P. Mucoadhesive ophthalmic vehicles: evaluation of polymeric low-viscosity formulations. J Ocul Pharmacol. 1994;10(1):83-92.

26. Ceulemans J, Vinckier I, Ludwig A. The use of xanthan gum in an ophthalmic liquid dosage form: rheological characterization of the interaction with mucin. J Pharm Sci. 2002;91(4):1117-1127.

27. Campoli-Richards DM, Chaplin S, Sayce RH, Goa KL. Netilmicin. A review of its antibacterial activity, pharmacokinetic properties and therapeutic use. Drugs. 1989;38(5):703-756.

28. Bonfiglio G, Scuderi AC, Russo G. Netilmicin: in vitro activity, time-kill evaluation and postantibiotic effect on microorganisms isolated from ocular infections. Chemotherapy. 2001;47(2):117-122.

29. Furneri PM, Garozzo A, Musumarra MP, Scuderi AC, Russo A, Bonfiglio G. Effects on adhesiveness and hydrophobicity of sub-inhibitory concentrations of netilmicin. Int J Antimicrob Agents. 2003;22(2):164-167.
Clinical Ophthalmology

\section{Publish your work in this journal}

Clinical Ophthalmology is an international, peer-reviewed journal covering all subspecialties within ophthalmology. Key topics include: Optometry; Visual science; Pharmacology and drug therapy in eye diseases; Basic Sciences; Primary and Secondary eye care; Patient Safety and Quality of Care Improvements. This journal is indexed on

Submit your manuscript here: http://www.dovepress.com/clinical-ophthalmology-journal

\section{Dovepress}

PubMed Central and CAS, and is the official journal of The Society of Clinical Ophthalmology (SCO). The manuscript management system is completely online and includes a very quick and fair peer-review system, which is all easy to use. Visit http://www.dovepress.com/ testimonials.php to read real quotes from published authors. 